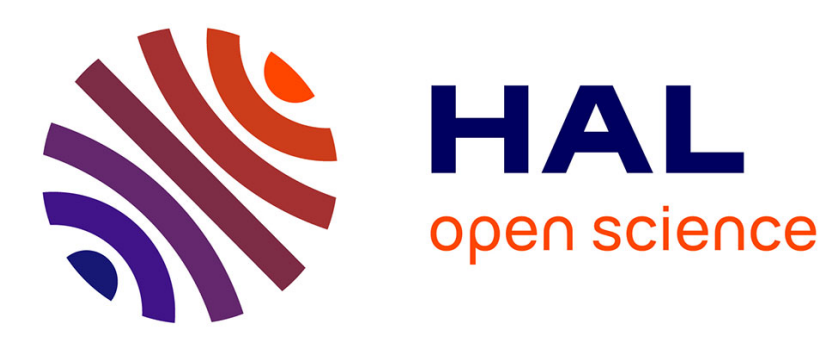

\title{
Large-Scale Innovative Projects as Temporary Trading Zones: Toward an Interlanguage Theory
}

\author{
Sylvain Lenfle, Jonas Söderlund
}

\section{To cite this version:}

Sylvain Lenfle, Jonas Söderlund. Large-Scale Innovative Projects as Temporary Trading Zones: Toward an Interlanguage Theory. Organization Studies, 2019, 40 (11), pp.1713-1739. 10.1177/0170840618789201 . hal-02390158

\section{HAL Id: hal-02390158 https://hal.science/hal-02390158}

Submitted on 4 Dec 2019

HAL is a multi-disciplinary open access archive for the deposit and dissemination of scientific research documents, whether they are published or not. The documents may come from teaching and research institutions in France or abroad, or from public or private research centers.
L'archive ouverte pluridisciplinaire HAL, est destinée au dépôt et à la diffusion de documents scientifiques de niveau recherche, publiés ou non, émanant des établissements d'enseignement et de recherche français ou étrangers, des laboratoires publics ou privés. 


\title{
Large-scale innovative projects as temporary trading zones: Toward an interlanguage theory
}

\section{Paper accepted for publication in Organization Studies \\ on june $18,2018^{1}$.}

\author{
Authors \\ SYLVAIN LENFLE (corresponding author) \\ Professor \\ Conservatoire National des Arts et Métiers \\ 2, rue Conté \\ 75003 Paris, France \\ \& Associate Researcher - i3/CRG, Ecole Polytechnique, Palaiseau. \\ e-mail: sylvain.lenfle@ lecnam.net \\ Tel: 00.33.6.84.98.49.18
}

and

\author{
JONAS SÖDERLUND \\ Professor \\ Department of Leadership and Organizational Behavior \\ BI Norwegian Business School \\ 0442 Oslo, Norway \\ e-mail: jonas.soderlund@bi.no
}

\footnotetext{
${ }^{1}$ The authors thank Rolf Lundin, Christophe Midler and Hans-Georg Gemunden ; Organization Studies Senior Editor Paul A. Spee and two anonymous reviewers for their invaluable comments and encouragements ; participants at the IRNOP 2015, EURAM \& EGOS 2016 Conferences for their feedback on earlier versions of the paper ; and seminar organizers and participants at the EHESS - Centre Alexandre Koyré for the History of Science and Technology in 2013 in Paris, in particular Cathy Dubois and Loïc Petitgirard for introducing them to Galison's work.
} 


\title{
Large-scale innovative projects as temporary trading zones: Toward an interlanguage theory
}

\begin{abstract}
Large-scale innovative projects (LSIPs) play a central role in arranging for exploratory and strategic opportunity seeking that transcends organizational and disciplinary boundaries. This paper outlines a theory that addresses the two most salient characteristics of such organizations: their extreme task uniqueness and high degree of interdisciplinarity. Drawing on the work of Peter Galison and the case of the Radiation Laboratory project, we introduce the notion of LSIPs as 'temporary trading zones' and posit the centrality of 'interlanguage creation' for coordinating such projects. We demonstrate that LSIPs foster and, indeed, practically necessitate the creation of an interlanguage via interaction among three core elements: linguistic representations, project management tools, and material representations. Summarizing our observations, we propose a process model of interlanguage creation in LSIPs; this model identifies five critical developmental phases that reveal how the three core elements interact to create an interlanguage.
\end{abstract}




\section{Introduction}

Coordination, i.e. the process of interaction that integrates a collective set of interdependent tasks, is one of any organization's central purposes (Okhuysen \& Bechky, 2009). This paper addresses coordination in a particular context: large-scale innovative projects (LSIPs). These projects are set up to explore technological and strategic opportunities, develop new scientific fields or tackle major societal challenges. They rely on multi-institutional collaboration, spanning professional and sectoral boundaries, to drive scientific and technology advancement (Corley et al., 2006; Tukiainen \& Granqvist, 2016; Hoffmann et al., 2017).

The combination of environmental volatility and knowledge specialization (Brusoni et al., 2001) has, over the last few decades, led to an increasing prevalence and magnitude of LSIPs (Brady \& Davies, 2004; Berggren et al., 2011; Tell et al., 2016; Flyvbjerg, 2017). Such projects have flourished in a number of contexts (see Morris et al., 2011) in the wake of big science developments (Galison \& Hevly, 1992); the large hadron collider project (Tuertscher et al., 2014) and major initiatives to deal with climate change (Komendantova et al., 2012; Morris, 2015) are all recent cases in point. In these settings, the "problem of coordination" (Grant, 1996; Gulati et al., 2012) is exacerbated by the field's novelty, by the interdisciplinarity due to the large number of participants involved, and by the relatively low level of familiarity among project participants (Majchrzak et al., 2012; Cattani et al., 2013). These projects often constitute a 'first of a kind' collaboration across different organizations and institutional domains to solve a knowledge-related innovation problem that is both novel and exceptionally challenging.

The theorization presented here targets two salient characteristics of LSIPs that together shape their underlying coordination problem. First is the task uniqueness that reflects the new scientific, knowledge, and technology fields being explored; hence these projects cannot rely on established structures and routines that are applicable in most other organizational settings. In fact, task uniqueness is these organizations' sine qua non: were the tasks not unique there would be little reason for organizing a project in the first place or for committing substantial resources to its management and coordination (Scranton, 2014). Absent uniqueness, that is, one could reasonably assume that extant routines and established procedures for coordination would be pressed into service However, on the contrary, in these project settings, problem-solving uncertainties and interdependencies 
are substantial and emergent, factors that render the underlying coordination problem even more complex (Obstfeld, 2012; Edmondson \& Reynolds, 2015). In these situations, technical problems and solutions are continually redefined (Tsoukas, 2009) and the knowledge of experts must be repeatedly transformed into knowledge that others can understand and recombine (Majchrzak et al., 2012).

The second salient characteristic is interdisciplinarity, which is a typical feature of "innovative organizational forms" (Pettigrew et al., 2003) and project-based organizing (Allen, 1977). However, adequately representing the "extreme task uniqueness" (Tuertscher et al., 2015) and distinctive "goal singularity" (Whitley, 2006) that characterize LSIPs requires that project actors draw from diverse, highly specialized, and previously disconnected knowledge domains (Brusoni et al., 2001; Hoffmann et al., 2017; Kaplan et al., 2017). Hence, these projects transcend sectoral, organizational, and professional boundaries; in many cases, they even transcend institutional and national boundaries (Scott et al., 2011). It follows that an LSIP is more interdisciplinary than are traditional innovative projects because it draws on both a deeper and more varied expertise of knowledge. Therefore, solving the LSIP's allocated task entails intense knowledge integration across boundaries as well as the production of new knowledge emerging at the edge of established knowledge and scientific boundaries (Tell et al., 2016).

The challenges associated with task uniqueness and interdisciplinarity turn many of our traditional coordination mechanisms on their head. For example: the task uniqueness of LSIPs precludes the existence a priori of encompassing coordination routines (Obstfeld, 2012); problems and roles are often difficult to define, even after the event (Whitley, 2006); and team member familiarity (Harrison et al., 2003) is low and must, to unravel the interdependencies involved, emerge throughout the problem-solving process (Tuertscher et al., 2014). These characteristics of LSIPs also make it difficult to establish the conventional coordination mechanisms of accountability, predictability, and common understanding (Okhuysen \& Bechky, 2009)

So, as coordination becomes more important in LSIPs for addressing the interdependencies and knowledge-related difficulties involved, it also becomes more difficult to achieve. This situation makes the LSIP setting well suited for explorations of how one should address the underlying coordination problem and how project actors 
coordinate at the 'limits of coordination'. Despite major advancements in our understanding of single-firm innovative projects, there is a paucity of research on how LSIPs - which cross institutional and organizational divides (Davies et al., 2009; Edmondson \& Reynolds, 2015; Hoffmann et al., 2017) - develop common ground when encountering higher levels of both task singularity (Whitley, 2006) and task complexity (Geraldi, 2009; Haerem et al., 2015). In particular, our current understanding of coordination could be enhanced by elaborating more advanced theoretical approaches based on the defining features of LSIPs as organizational forms (cf. Sydow et al., 2004; Manning, 2017).

In this endeavor, we rely on the strategy of 'borrowing' theory from neighboring disciplines; that is, we explain phenomena in one theoretical domain using ideas borrowed from another (Floyd, 2009; Markóczy \& Deeds, 2009). Indeed, one of our paper's principal aims is to develop new concepts and theories by describing LSIPs as temporary trading zones, a concept proposed by the historian of science Peter Galison. As documented in our empirical account to follow, a major hurdle raised by the combination of extreme task uniqueness and interdisciplinarity is the need to create an 'interlanguage' and thereby facilitate coordination among participants. By focusing on the creation of an interlanguage, we shed new light on the problem of coordination in LSIPs by adding to our understanding of the dimensions, elements and process of interlanguage creation.

More specifically, this paper makes three theoretical contributions. First, it proposes the temporary trading zone as a new way to conceive of coordination processes in LSIPs. Second, it provides a framework that connects the interlanguage's core elements to LSIPs qua temporary trading zones. Third, we posit a process model of interlanguage creation in LSIPs by identifying critical phases in the development of such a language. Besides enhancing our understanding of the coordination problem more generally and of how it is solved in LSIPs, this framing yields insights and tentative answers to several fundamental questions in the development of theory on LSIPs. These questions include: Why do LSIPs exist? How do these projects evolve? What factors explain their success or failure? Our framing draws on a practice-oriented perspective and is grounded in an analysis of what actually transpires on these projects: how they bring about coordination, interlanguage creation, and knowledge integration (cf. Manning \& Sydow, 2011; Majchrzak et al., 2012). 
We proceed by first presenting the theoretical background and highlighting previous studies related to innovative projects in general and to LSIPs in particular. Then follows our casting of LSIPs as temporary trading zones. We subsequently offer an empirical illustration before presenting the central dimensions and key elements of our theoretical framework. Finally, we propose a process model of interlanguage creation and offer suggestions for future research.

\section{Innovative projects and the problem of coordination}

The question of interdisciplinary coordination is central in organization theory and innovation studies (Davies, 2013), and it is viewed as an important problematic in new organizational forms and interorganizational collaborations (Whitley, 2005; Manning, 2017). Interdisciplinary coordination has been conceptualized as a fundamental problem of 'integration' since Lawrence and Lorsch's (1967) landmark study, which defined integration as "the process of achieving unity of effort among the various subsystems in the accomplishment of the organization's task" (p. 4). The same problem is no less central to innovation management, an area in which practitioners draw on the integration of expertise across knowledge and professional boundaries (Allen, 1984; Van de Ven, 1986 ; von Hippel, 1990). For instance, Hoopes and Postrel (1999) address the importance of "glitches" in project failure; these occur when, to the entire project's detriment, individual project actors lack a common understanding of its basic premises.

Key insights have been offered by two streams of literature: one, following Lawrence and Lorsch (1967) and their emphasis on the role of integrative structures; and the other, following Allen (1977), with a stronger focus on integrative processes such as information flows and the use of boundary-spanning mechanisms. The first research stream explores structural arrangements, such as project teams and matrix solutions, which foster integration. In this line of research, a sophisticated use of the integration concept is suggested by the Harvard studies on new product development (NPD) projects (Clark \& Fujimoto, 1991; Wheelwright \& Clark, 1992; Iansiti \& Clark, 1994). In these studies, integration is a dynamic capability that amounts to more than communication and coordination across functional boundaries because it also entails the "proactive generation of new knowledge" (p. 602). 
That body of research yields a helpful depiction of internal and external integration mechanisms, which correspond, to a great extent, to observed characteristics of "heavyweight development teams" that rely on "integrated problem solving" (Clark \& Fujimoto, 1991). This literature also emphasizes the need to increase team autonomy when the goal is innovation of a more radical kind (Wheelwright \& Clark, 1992). However, two drawbacks of this approach are that it fails to grasp how integration unfolds within project teams or to identify any specific practices associated with the integration process across project teams comprising diverse disciplinary domains. As remarked by Hoopes and Postrel (1999), the actual results of such integration - and its particular effects on how the project unfolds - remain very much a mystery (for more recent reviews, see Tell, 2011; Tell et al., 2016), which could also help account for the scholarly literature not having fully grappled with the reasons why interface and knowledge integration glitches occur or what might be done to curb them.

The second, complementary line of research focuses on integration processes per se - more precisely, on the evolution of coordination mechanisms that span boundaries within and across organizations. Carlile (2002; 2004) develops an integrative framework that distinguishes three processes critical for such boundary spanning: transferring, translating, and transforming. These processes correspond to increasingly complex situations in which novelty and the diverging interests among actors complicate the process of coordination (Lightart et al., 2016). What is most interesting for our study is that Carlile emphasizes the "foundational role" of the creation of a "common lexicon" between actors who wish to coordinate across boundaries. Carlile makes several valid points concerning the role and nature of this common lexicon, but he does not describe how it emerges. We also note that, in his study, lexicon refers mainly to an agreement on differences and dependencies in the design of "known objects" in a NPD project involving relatively mature technologies. Of course, the degree of uniqueness is rather limited in that case; so even though the substantial interdisciplinarity requires intense collaboration among actors, they could rely (for the most part) on established routines and existing concepts.

Kellogg et al. (2006) develop this framework further and identify three main practices enabling cross-boundary coordination: display (rendering work visible to others), representation (rendering work legible via documents and/or PowerPoint 
presentations), and assembly (juxtaposing work through modification and recomposition). Their discussion of these results includes an insightful description of the coordination processes inherent in interdisciplinary projects, showing that identification of differences and intense knowledge dialogue need not be required for the success of temporary cross-disciplinary teams. This analysis seems especially relevant to noninnovative projects involving extensive repetitiveness, such as the web agency studied in their research (Obstfeld, 2012), but is probably less applicable to analyzing coordination in LSIPs.

Deepening these ideas, Majchrzak et al. (2012) show how project teams working on innovative tasks can overcome the challenges associated with knowledge integration by relying on a set of "knowledge transcending practices." These practices describe how sensemaking evolves over time in "novel projects" and how "knowledge transformation occurs between different languages and perspectives without deep-knowledge dialogue" (Majchrzak et al., 2012, p. 963). The latter, the authors state, is crucial because prior research has raised concerns about the necessity of a "deep-knowledge dialogue" in light of time and resource restrictions (Edmondson \& Nembhard, 2009).

However, Majchrzak et al. (2012) concede, their research has clear limitations: it applies to small cross-functional teams consisting of company employees and lasting for just a few weeks; and it concerns the development of fairly uncomplicated and modest innovative solutions (e.g., quality control processes). So, in relation to our paper, the task uniqueness in their cases was modest and the degree of complexity and interdisciplinarity was low (since all participants were employed by the same firm and had prior experience of working together). For these reasons, there was no real need to engage in a deep dialogue that revealed contrasting assumptions and fundamental knowledge differences. And since the task at hand was novel but not radically innovative, there was no need to develop a new language for overcoming coordination problems.

The contributions described in this section offer useful guidelines as we seek to understand the coordination problem in LSIP. Earlier studies underscore the importance of language in establishing coordination in highly innovative settings (see also Ancori et al., 2000). However, that research mainly deals with projects unfolding within an organization - albeit large ones, such as automotive manufacturers (Clark \& Fujimoto, 
1991; Cusumano \& Nobeoka, 1998) - and did not seek to develop theories of coordination in LSIPs per se.

Beyond the traditional challenge of interdisciplinarity, LSIPs have characteristics that further complexify the coordination process: the field's novelty combined with the organization's uniqueness. Thus, as both Whitley (2006) and Obstfeld (2012) point out, these actors cannot at first rely on role stability, routines, and proximity that - for less innovative projects unfolding within a single organization - provide a common background and form the basis of coordination (cf. Valentine \& Edmondson, 2015).

Therefore, focusing on LSIP's uniqueness and interdisciplinarity reveals how important it is to overcome challenges stemming from the lack of familiarity and the lack of an established 'common lexicon', both of which are critical for coordination and knowledge integration in such settings. Accordingly, we adopt a practice-oriented perspective and elaborate on the trading zone concept of Galison (1997), who emphasizes that coordination depends on interlanguage creation and focuses on how both coordination and knowledge integration are accomplished in these settings.

\section{Large-scale innovative projects as temporary trading zones}

In our quest for an accurate account of coordination in LSIPs, we draw on Galison's (1997) Image and Logic - a book that analyzes the evolution of the practices of scientists working in the field of atomic physics. Galison focused on the question, which is central also to our research, of coordination between three "physics cultures": theorists, experimenters, and instrument builders. Image and Logic is a fascinating and meticulous description of how modern physics evolved from a "workshop" type of science in the early 20th century to the huge "factory of physics" developed after World War II at such academic institutions as Stanford University and MIT. The greater size and complexity of postwar experiments (e.g., complex bubble chambers, large particle accelerators) increased both the importance and the difficulty of coordination. The pressure to stay ahead of the game also paved the way for a strong focus on delivery and development times. The latter further exacerbated coordination problems and so made coordination even more important.

Galison described the process of coordination by introducing the concept of a trading zone as "an intermediate domain in which procedures could be coordinated 
locally even when broader meanings clashed" (1997, p. 46). He demonstrated that there are often profound differences (even paradigmatic ones) among the various cultures in physics and between scientists and engineers. Yet, Galison established that, notwithstanding such differences, "there can be exchanges [coordination], worked out in exquisite local detail, without global agreement" (p. 46) and that overcoming these differences is paramount to most innovative achievements.

To construct his trading zone framework, Galison relied on anthropological linguistic work that indicated how goods were successfully exchanged between groups molded in radically different cultures that spoke different languages. In his own borrowing from linguistics, Galison argues for a process of "language creation" in the trading zone - which runs counter to the paradigm, followed by most work in the sociology of science literature, of 'translation' (Callon, 1986). So rather than depicting the movement across boundaries as one of "translation (from theory to experiment, from military to civilian science, or from one theory to another), it will prove useful to think of boundary work as the establishment of local languages - pidgins or creoles - that grow and sometimes die in the interstices" (Galison, 1997, p. 47). Although research has explicated the nuances of translation and demonstrated that it is more than a mechanistic process of matching terms (Yakhlef, 2002), the dynamic of translation differs considerably from Galison's idea of language creation. His work demonstrates in particular that creating an 'interlanguage' is a core element of coordination in these settings, which we believe is Galison's main theoretical contribution.

An important aspect of Galison's work is his adopting an expanded definition of the term language, a definition that increases his framework' applicability to our context and that makes it even more relevant to organization studies. Galison left no doubt regarding this question when reflecting, in subsequent work, on the trading zone concept:

the language of science does read, quite literally, as language: propositions, statements, observations, hypotheses and conditionals are all recognizably linguistic even if technical in scope. But at other times practices do not necessarily form linguistic objects, in a strict sense. Diagrams and symbols, for example, have their own combinatorial logic. ... I'm interested in language in an expanded sense that would embrace such symbol language - whether computer codes, abstract algebra, formal logic, or the calculations of quantum physics. (Galison, 2010, p. 43; our emphasis) 
It is also apparent from Galison's later writings that he views various "objects" as constituting a form of language. This perspective leads Galison to speak of "wordless pidgin or wordless creole" to name "material or symbolic objects [that] are also a form of language" (2010, pp. 43-44). Thus:

Images, symbol systems, calculational and diagrammatic schemes - even complex objects - could be part of a generalized notion of language that is far from 'just words'. Indeed, language, as I want to use it, is a regular yet flexible apparatus that may take many forms, from the recognized, everyday 'natural world languages', to the myriad, systematic registers in which we communicate. (p. 44)

Here Galison, despite criticizing the concept of 'translation', recognizes the affinity of his work to the research of Star and Griesemer (1989) on boundary objects. Yet the ideas of the trading zone and interlanguage creation are far wider in scope than are boundary objects - even though (as we shall discuss) the latter are key to facilitating the former.

As underscored by Gorman et al. (2004, p. 64), the trading zone is more than a metaphor. They argue that, for developments in many technology areas, the actors involved (e.g., engineers and scientists) must construct their own "dialect" so they can communicate and interact more effectively. For example, there are "multidiscliplinary trading zones" in nanotechnology that feature a division of labor among groups (Gorman, 2002). In such cases, the groups may develop a specialized dialect, a kind of "nanocajun", to coordinate activities; but they may also adopt a full-out interdisciplinary approach in which all participants engage in discussions concerning all aspects of research and development.

The purpose of a trading zone is ultimately to enable the sharing of expertise and disciplinary knowledge toward the end of achieving a common and unique goal. One key assumption in the literature on trading zones is that their members must develop a 'creole', or a project-specific interlanguage that fosters coordination. The unique and interdisciplinary nature of such collectives leads us to presume that, in a trading zone's initial phase, they lack an overarching interlanguage and that considerable management and organizing effort must be directed toward establishing one, thereby facilitating the integration of disciplinary knowledge and improving the odds of project success. Note that this is an important difference from the projects studied by Carlile (2004), Kellogg 
et al. (2006), and Majchrzak et al. (2012), which were more repetitive, less innovative, and thus more likely to rely on established organizational routines and concepts.

\section{Inside the trading zone: An illustrative case}

To show what Galison means by the creation of a new language and to explain how it facilitates coordination across participants in the trading zone, we find it useful to consider one of the detailed cases presented in his (1997) Image and Logic: MIT's Radiation Laboratory (hereafter, 'Rad Lab') project. The Rad Lab project was established at the end of the 1940s to design and develop radars that could be used in combat. It operated under the leadership of Dr. Lee Alvin Dubridge until the end of 1945 and, at its peak, had a staff of nearly 4,000 (see Buderi, 1996; Brown, 1999). Key aspects of the Radar Project were its many participants, its high degree of innovativeness and uniqueness, and (owing to the range of expertise needed for project completion) its interdisciplinarity. The technology was radically new and its development required new types of coordination between disciplines, most notably engineering and theoretical physics. Thus, the project involved 20 universities and 40 autonomous companies that included Western Electric, RCA, and General Electric. The Rad Lab was the project's central node. Like other wartime endeavors, it brought together scientists (theorists and experimenters) and engineers for the purpose of designing - under considerable deadline pressure - extremely innovative technical devices.

In order to foster coordination between scientists and engineers, the Rad Lab adopted a highly innovative structure. It ignored convention and was not organized by technical expertise or discipline but rather by components of the system (modulator, magnetron, antenna, receiver, and indicator) - and, after March 1942, by the end product's application (ground systems, ship systems, etc.; see Figure 1). As a result, "the physical architecture [of the lab] closely matched the electronic architecture" (Galison, 1997, p. 817). That approach did not respect the distinctions typically made between physicists and engineers:

W. Turner, for example, was an electrical engineer with a desk adjacent to that of $\mathrm{H}$. Neher, a physicist trained in experimental cosmic ray investigation. W. Hall, who had been an electrical engineer working for MGM doing sound recording, now shared the 
indicator corner with A. J. Allen, a physicist and electrical engineer, and E. C. Pollard, a physicist who in 1940 was an assistant professor at Yale. (Galison, 1997, p. 817)

\section{Figure 1. Physical Layout of the MIT Radiation Laboratory (Galison, 1997, p. 819)}

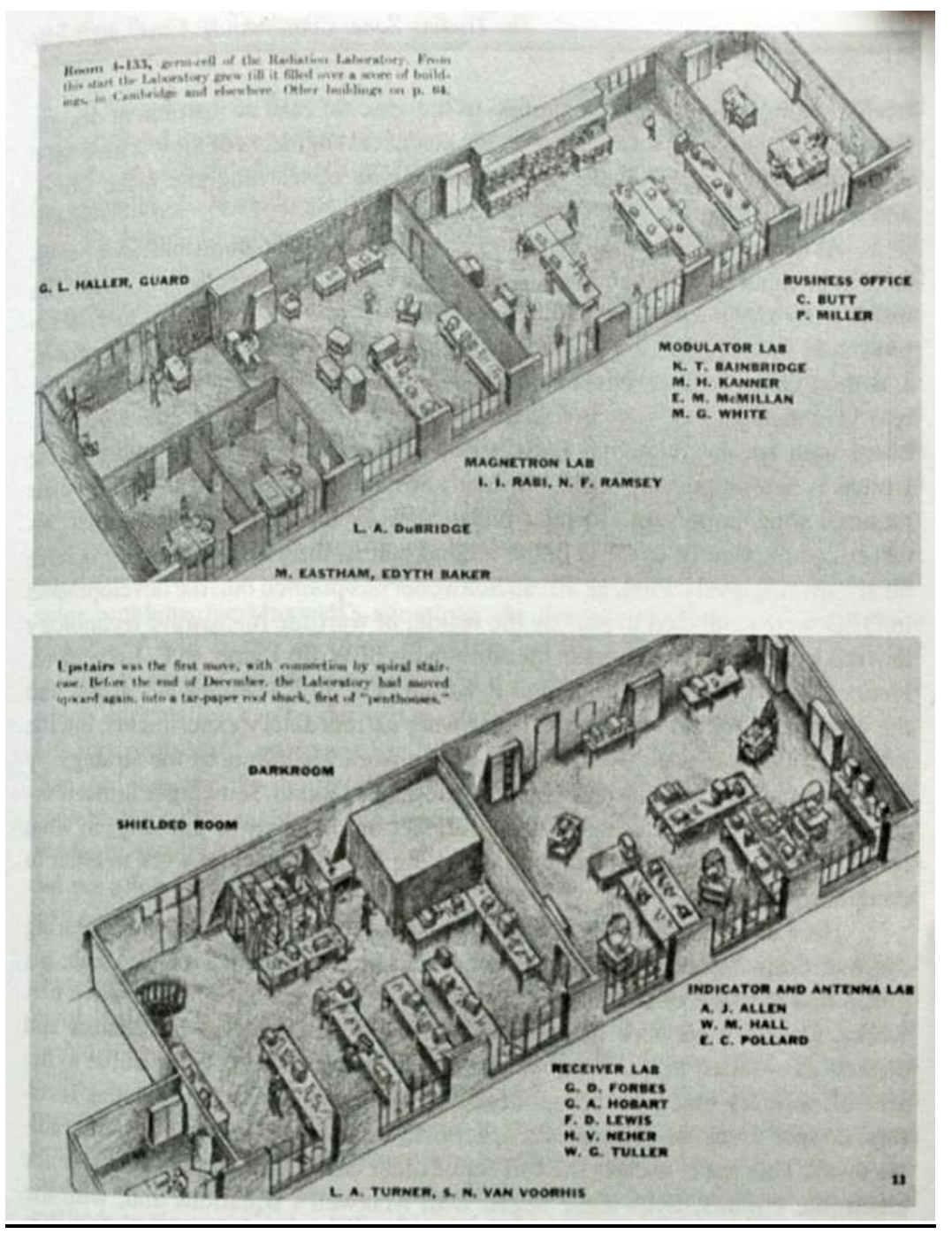

The Rad Lab project was deliberately designed to encourage face-to-face communication between the involved experts. This organization led to a new kind of interaction among the different disciplines - namely, one in which engineering goes beyond the application of theory and leads to the reconfiguration of both disciplines. To demonstrate this point, Galison (1997) focuses on the project actors' practices. In particular, he analyzes in detail the work of Julian Schwinger (who in 1965 would earn the Nobel Prize in Physics) at the Rad Lab. Schwinger worked in the lab's theoretical division and "had the task of developing a usable, general account of microwave 
networks" (p. 820), a critical question in the design of radar components. The problem was that ordinary network theory was useless for radar design. Therefore, Schwinger "began with Maxwell's equations and, with the help of his coworkers, derived a set of rules by which engineers and physicists could make practical network calculations" (p. 820). This first approach proved to be too complex; however, and

as the war progressed and Schwinger assimilated more of the 'good enough' and inputoutput culture of the Rad Lab, he began to abandon the physicist's abstract scattering theory of electromagnetism and to search for the microwave analogue of the electrical engineers' more practical representations: simple 'equivalent circuits' that imitated just the relevant aspects of the components. (p. 821)

As Galison explains, this was an old technique among electrical engineers. Thus, in Galison's words, the engineers "put the complicated physics of the loudspeaker's electromechanically generated sound into a 'black box' and replaced it in their calculations with equivalent electrical components" (p. 821). Schwinger thereby enabled the engineers to make their calculations "without entering each time into the details of complex boundary-value problems for Maxwell's equations" (p. 821).

Yet, there was much more at stake in this process than 'translating' microwave physics into engineering syntax or, as in Carlile's framework, the establishment of a common lexicon. Galison demonstrates that what actually evolved was a "true pidgin" a new language that facilitated coordination between the disciplines of physics and engineering. One especially difficult problem was "the determination of equivalent circuits for waveguides (long hollow metal boxes) involving discontinuities (protrusions, gaps, dividers, etc.)" (1997, p. 821; see Figure 2). That task was beyond the capacity of prewar physics, so Schwinger devised theoretical methods to circumvent the difficulties of such geometries. 


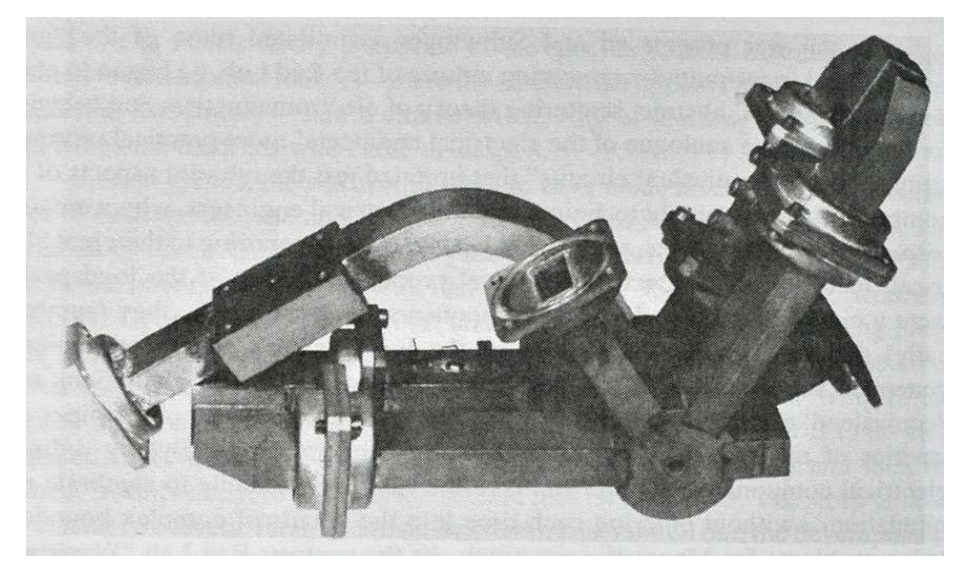

Thus, he produced
a kind of simplified jargon (or pidgin) binding elements of the language of field theory with elements of engineering equivalent circuit talk [see Figure 3; our remark]. ... [He] had manufactured a meeting point that both physicists and engineers could understand and that both could link to their larger concerns - on one side to the concepts of Maxwellian field theory, on the other to the practices of radio engineering. (p. 822)

The fundamental breakthrough here was that "the 'glossary' was identifying newly calculated theoretical elements with recently fabricated fragments of microwave circuitry: neither was part of the prior practice of either the theorists or the radio engineers" (Galison, 1997, p. 824; our emphasis). In this way, the constant interaction of physicists and engineers working on the project enabled the creation of a new and "powerful, locally understood language" (p. 833) that fostered coordination between two distinct occupational groups. This outcome was entirely different from a mere translation between physics and engineering. Galison emphasized the key role that co-location and wartime pressure played in this process: "Under the gun, the various subcultures coordinated their actions and representations in ways that seemed impossible in peacetime; thrown together they began to get on with the job of building radar" (p. 827). From this perspective, this project 


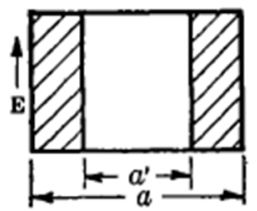

Cross sectional view

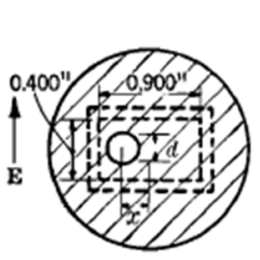

Front view

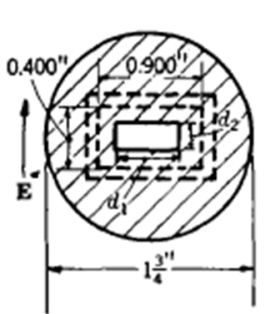

Front view

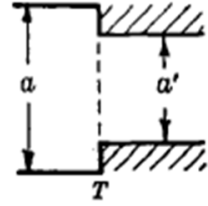

Top view Fro. 4:1-1.

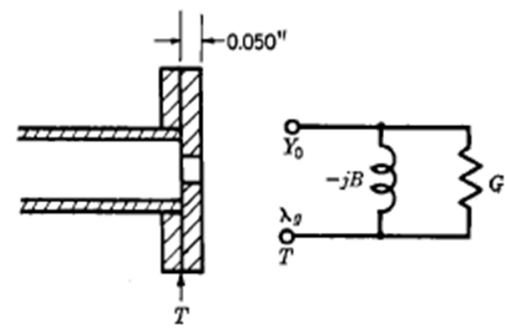

Side view Fra. 4-10-2.
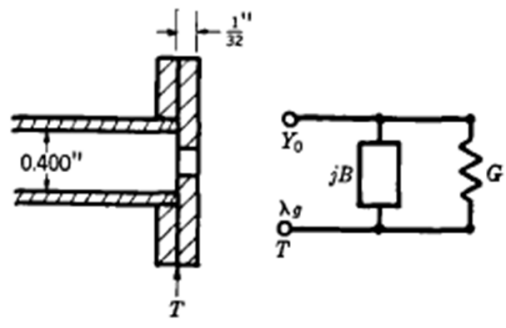

Side view

Equivalent circuit

offers us a picture of the trading zone as an epistemic matter and as a physical location. ... The disposition of personnel indicates that engineers and physicists worked within sight of one another. ... The success [of the MIT Rad Lab] was directly related to the creation of such common domains in which action could proceed even though the physicists and engineers entered into the exchange with radically different understandings of the machinery and techniques involved. (p. 830)

To strengthen his theory, Galison provided examples of projects plagued by the absence of such common domains - for instance, the Time Projection Chamber (TPC) project conducted at Stanford from 1974 to 1985 (Galison, 1997, chap. 7). In that project, experts were scattered among different locations; this dispersion prevented the creation of an interlanguage, which in turn led to major coordination problems remaining unresolved. Hence, the project manager, when confronted with the project's slippage and 
lack of unified understanding, wrote a memo urging that "next time [we] ... build a circus tent to house everyone" (p. 619).

\section{A theoretical framework for coordination in LSIPs}

Both the Rad Lab case and our review of the literature indicate that there are several intriguing links between interlanguage creation and organizing across knowledge boundaries; these connections are viewed as critical in prior studies of highly innovative and interdisciplinary projects, but so far they have had little effect on theoretical analysis of the LSIP as a particular organizational form. This state of affairs makes evident the value of better connecting innovation management with the literature on project-based organizing (Davies, 2013) and of identifying, in particular, how project managing relates to the management of innovation. Yet, research on innovation management seldom treats managing a project as the means to create an interlanguage and, conversely, the projectbased organizing literature seldom views interlanguage creation as a central concern when addressing coordination problems and processes in LSIPs.

Our main argument is that an LSIP can be viewed as a temporary trading zone that fosters the ongoing development and nurturing of an interlanguage for use at the boundaries of knowledge domains. Such a framing is conducive to a theory that better addresses the role of projects in integrating diverse knowledge across boundaries. In the LSIP setting, for instance, actors from different organizations, and disciplines must coordinate their respective knowledge processes under time and budget constraints. Even the most basic coordination process requires the establishment of a common lexicon through words, symbols, and objects (Carlile, 2002; 2004). The fundamental question, which the management literature continuously emphasizes but seldom theorizes about, is how coordination and communication among the individuals involved in such projects unfolds - especially when the actors initially lack a common ground due to disciplinespecific terminologies and languages.

These features are, of course, exacerbated in LSIPs. As we have seen, answers to this question tend to emphasize, on the one hand, the role of project creation, co-location of personnel, and the project manager's function in fostering coordination (e.g., Clark \& Fujimoto, 1991) or, on the other hand, the cross-boundary coordination processes 
occurring among those involved in the project (see e.g. Carlile, 2002; Kellogg et al., 2006; Majchrzak et al., 2012).

However, there are two main obstacles in our advance toward a more elaborate account of coordination in LSIPs. First, although research has confirmed the centrality of a common lexicon in fostering coordination, it has not adequately addressed the nature and emergence of such lexicons. More specifically, we must learn more about the act of interlanguage creation for the organizing of these innovative projects and should consider that to be an integral part of solving the coordination problem. This approach is especially germane to LSIPs because these projects involve a greater variety of knowledge bases and areas of expertise. As Galison (1997) emphasizes, and as our paper confirms, such language creation is one of the main challenges in projects that are non-routine, innovative, and interdisciplinary.

Second, although previous research has explored several key facets of projectbased organizing - including project creation, team structures, and coordination mechanisms - it has not fully accounted for the nature of the project's setup and the consequences of that setup for interlanguage creation. Indeed, the analysis must incorporate specific project features (e.g. co-location) because only then can we improve our understanding of how interlanguages develop and better grasp their role in the ongoing practices of project managing and organizing.

It follows that exploring these two obstacles in greater depth would also enable better integration of earlier research on the structural and processual features of coordination. By taking this approach while focusing on interlanguage creation, we develop a theory that emphasizes the significance of organizing devices - including project creation and co-location - as well as the mechanisms required to foster the process of cross-boundary coordination. Such an understanding should comprise not only the nature of interlanguage (what it is and the role it plays) but also its creation (how the interlanguage is created and how it evolves during the project's lifetime).

Toward the end of enriching academic inquiry into the ontology and emergence of LSIPs, we shall elaborate on the idea of these projects as temporary trading zones. Hence, we offer the following definition.

A large-scale innovative project is a temporary trading zone dedicated to creating an interlanguage that fosters coordination and knowledge integration 
across disciplinary boundaries to solve a unique, complex, and advanced form of innovation problem.

More precisely, we hypothesize as follows. In many organizations, setting up a 'heavyweight' project organization enables cross-disciplinary coordination processes to unfold (Carlile, 2002; Kellogg et al., 2006; Majchrzak et al., 2012). The outcome is an 'interactive zone' (i.e., a physical and spatial arrangement of the team's work space), which fosters creation of an interlanguage that in turn facilitates coordination among the different expert groups involved. This was the essence of the Rad Lab project.

We thereby bridge the previously mentioned structural and processual approaches to coordination adopted by the innovation management literature. We also argue, based on prior literature and the empirical observations presented here, that an interlanguage has three primary elements in our research context: linguistic representations, project management tools, and material representations. The presentation of our framework proceeds as follows. In this section we analyze the two main dimensions of a trading zone, organizing devices and interlanguage; in the next section, we propose a practice-oriented process model that explains how an interlanguage is established and how it develops over time.

The first 'dimension' of our proposed framework is represented by organizing devices. Evidently, the creation of a dedicated and formal organization (e.g., the Rad Lab) is prerequisite to the creation of an interlanguage. We therefore concur with the literature on innovation management, which emphasizes the role of project creation as an essential step fostering interdisciplinary coordination (Bacon et al., 1994; Tushman \& Anderson, 1996). Indeed, in works ranging from the Polaris Special Projects Office (Sapolsky, 1972) to Clark and Fujimoto's (1991) heavyweight development teams, research on projectbased organizing has demonstrated (i) the importance of setting up a dedicated team, of co-location, and of establishing project review mechanisms for overcoming coordination problems between boundaries as well as (ii) the fundamental challenges associated with establishing such arrangements in large organizations that are organized primarily by function (Clark \& Fujimoto, 1991).

In these regards, it is evident from Galison's (1997) work that World War II's LSIPs marked a turning point. Undertakings such as the Radar Project and the Manhattan Project played a key role in developing new collaborative practices and new forms of 
trading zones, where interlanguage creation was fostered by the emergence of "new visible structural arrangements - both physical and social - in which action can proceed" (Vaughan, 1999, p. 922) or what Galison refers to as an "interactive zone" (1997, p. 830). In analyzing how innovative projects and goal-centered laboratories function, Galison is crystal clear on this matter: he states that a trading zone is both "an epistemic matter and a physical location" (p. 830; our emphasis).

This statement was embodied by the Rad Lab, which was not a traditional scientific laboratory but rather a temporary, goal-centered project on which participants worked in new and close proximity. It was oriented toward a concrete and hands-on goal ("building radars") with tight interdependencies among the tasks involved, it had a clear and powerful managerial hierarchy, its structure used co-colocation to organize the interaction between disciplines, and time was of the essence during the entire organizing process. Bringing scientists and engineers together under the same roof and authority led to new types of relations; it created a different kind of interactive zone, which was crucial for the coordination of expertise. As described previously, this approach led physicists and engineers to create a new type of language so they could understand each other - a 'pidgin' that was, strictly speaking, neither engineering nor physics yet facilitated communication among areas of expertise and design processes.

We therefore consider project creation and the establishment of an interactive zone as a fundamental initial step in the coordination process; hence, more generally, interlanguage creation can be viewed as the raison d'être of heavyweight projects in a more general sense (Clark \& Fujimoto, 1991). Such projects are established to overcome the limitations of traditional, functional structures (Allen, 1977) and to facilitate intense collaboration among disciplinary experts rooted in different localized and idiosyncratic knowledge practices (Sole \& Edmondson, 2002; Lindkvist, 2005).

Therefore, our framework's second dimension is interlanguage creation. We posit that, by creating an interactive zone, LSIPs mold a context with the potential to foster the development of an interlanguage. As mentioned earlier, the importance of a common lexicon to facilitating coordination has been clearly identified in the literature on innovation management. Prior research has zeroed in on the problem of different disciplines agreeing on terminology (see Carlile, 2002) and creating new knowledge through a process of mutual influence and collaborative emergence (Majchrzak et al., 
2012). Without a common ground, participants in the process of knowledge integration will be unable to evaluate each other's input, which can lead to misunderstandings and misattributions (Hoopes \& Postrel, 1999;).

The $\mathrm{Rad}$ Lab case demonstrates the importance of interlanguage creation, i.e. something that was not there at the beginning and which was considered necessary for fostering interdisciplinary coordination. Indeed Schwinger's formula resulted from his interaction with engineers and, in the end, enabled the two groups to coordinate their actions. The case also exemplifies Galison's (2010) suggestion that an interlanguage should be understood in an expanded sense and not "just words" (Galison, 2010, p. 44). Therefore both the literature and the Rad Lab case demonstrate that interlanguage evolves as the interplay among three elements: linguistic representations, project management tools, and material representations. This deconstruction allows for a nuanced and finegrained analysis of how LSIPs unfold. We discuss these three elements in what follows.

1. Linguistic representations. This element, which is central to Galison's work, is likewise fundamental in our framework. It also appears in the literature on innovation management; for example, Nonaka and Takeuchi (1995) describe the role played by "figurative language" (p. 13), such as metaphors and analogies, in the knowledge-creating process. Seidel and O'Mahony (2014) have more recently examined the process of concept creation and the role that language plays in it. From the work of Clark and Fujimoto (1991), Nonaka (1994), Midler (1996), Gorman et al. (2004), and Seidel and O'Mahony (2014), it is evident that the creation of a project-specific language is a fundamental characteristic of many successful innovative projects. In fact, they demonstrate that a task at the core of setting up any project organization is to design, negotiate, and implement the concept that justifies the project.

A clear indication of the necessity for such a project-specific interlanguage - to which any researcher who has worked on a project team will attest - is the difficulty of understanding not only the remarks of others in project meetings but also the project's overall goal, what it should produce, and who should benefit from it. As a case in point, the Renault Logan project (Jullien et al., 2013) makes one appreciate how difficult yet crucial it is for the firm to define an "entry vehicle" (as distinct from a "low-cost vehicle") when it has never built such a car and is unconvinced that doing so would be profitable (Midler, 2013). This was fundamental to defining the project's identity and thereafter to 
negotiating and trading with regard to its different functions and across the areas of expertise involved.

2. Project management tools. Galison's demonstrates how, in highly complex and innovative endeavors such as the TPC project, communications are facilitated by such project management (PM) tools as PERT, phased planning, task partitioning, designating system engineers and project managers. Indeed, the essence of project management is to work at the interfaces and organize cross-boundary coordination in a way that facilitates integration (Davies, 2017). Thus, the PM toolbox itself can, as noted by Galison in connection with the TPC project, be viewed as a language for enhancing coordination and as a measure to promote the generation of linguistic representations.

It is therefore not surprising that several management scholars have studied how PM tools, such as schedules, serve as boundary objects (Yakura, 2002; Chang et al., 2013) and how PM amounts to a new language that is capable of fostering coordination (Linehan \& Kavanagh, 2006). In the same vein, one could follow Johnson (2002) in arguing that the reliance of large-scale innovative military and space projects on the tools and language of systems management reflects the need for a new language to manage the interfaces between components and disciplines. Hence, we agree with Engwall (2012, p. 611), who argues that PM tools play three different but equally important roles: as a boundary object for technical coordination of actions and expectations; as a political feature for legitimacy and trust building; and as a cognitive means for "the social construction of a predictable future."

3. Material representations. There is now an extensive literature on the fundamental role of material representations (Seidel \& O'Mahony, 2014) in the innovation process - be they prototypes, simulations, or other material objects. They act as boundary objects that can foster coordination between experts with different backgrounds and helps to overcome the problem memorably summarized by Weick (1979, p. 133): "How can I know what I think, until I see what I say?" Our intention here is not to contribute to this research stream but rather to emphasize the importance of material representations as a central element in interlanguage creation.

The research of Henderson (1999), Carlile (2002), Sapsed and Salter (2004), Ewenstein and Whyte (2009), Nicolini et al. (2012), and Ioro and Taylor (2014) addresses the various roles that material representations play in the design process, and it generally 
demonstrates their importance for the organization of innovative projects as well as their capacity to help establish new concepts and ways of communicating. Material representations were essential to Galison's (1997) study and have been highlighted in related work on cross-boundary coordination. For instance, Enberg et al. (2006) show how the physical product had a central role in creating a shared understanding and facilitating communication among engineers involved in an innovative NPD project, Nonaka (1994) also underlines the importance of "artefacts" for the establishment of a common understanding - that is, in addition to the common lexicon that an innovative project's team members can use to discuss what needs to be done and how best to do it.

Figure 4. Dimensions and Elements of the Temporary Trading Zone for Interlanguage Creation

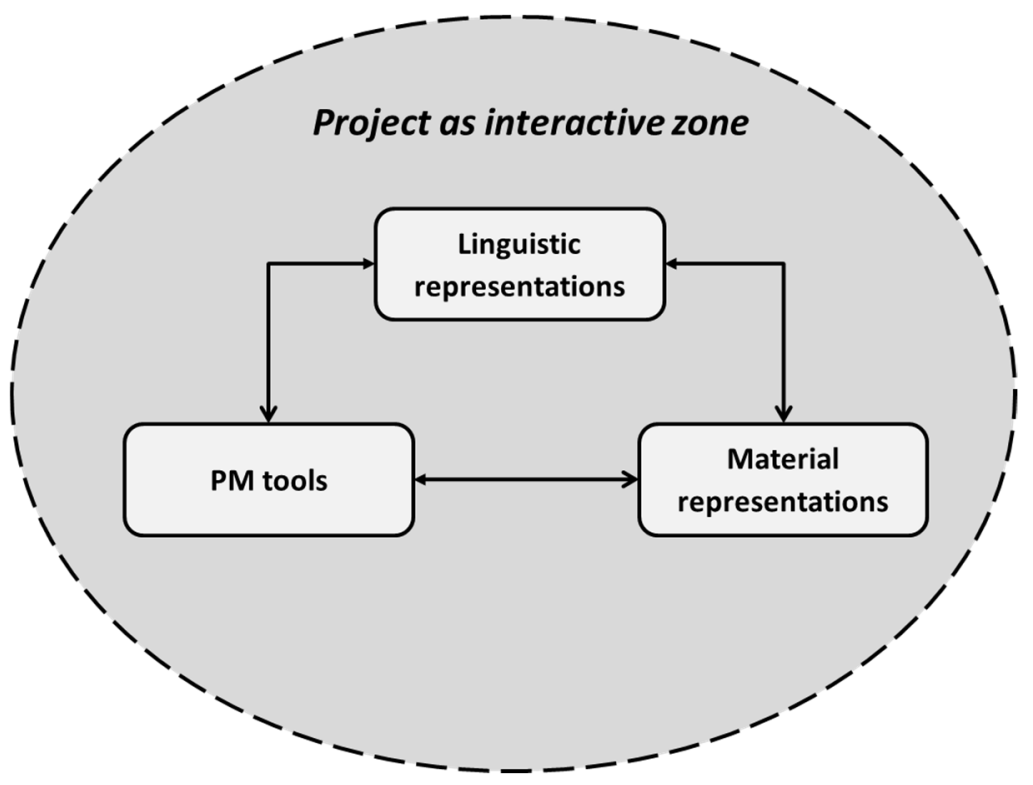

These components are summarized in Figure 4, which presents a schematic visualization of the interlanguage creation context and how our framework's dimensions and elements are interlinked. This figure illustrates the two key dimensions of our suggested framework: (1) the organizational dimension, in terms of which the project is an interactive zone (established through various organizing devices) that sets the stage for (2) the interlanguage dimension, whereby the creation of such a language is a function of three core interacting elements: linguistic representations, project management tools, and material representations. Table 1 summarizes the trading zone framework's two dimensions and its three elements. 
Table 1. The Interlanguage Framework: Dimensions and Elements

\begin{tabular}{|c|c|c|c|c|}
\hline Dimension & Activities & Primary mechanisms & Consequences & $\begin{array}{l}\text { Issues and } \\
\text { problems }\end{array}$ \\
\hline $\begin{array}{l}\text { 1. Organizational } \\
\text { dimension: Organizing } \\
\text { devices }\end{array}$ & $\begin{array}{l}\text { Setting up the formal } \\
\text { project organization, } \\
\text { integrating diverse } \\
\text { expertise - e.g., } \\
\text { among engineers and } \\
\text { scientists, among } \\
\text { developers and testers. }\end{array}$ & $\begin{array}{l}\text { Project management as a } \\
\text { mechanism that } \\
\text { integrates across } \\
\text { functions and thus } \\
\text { generates knowledge } \\
\text { among project experts; } \\
\text { the key role of } \\
\text { heavyweight project } \\
\text { management and teams } \\
\text { in this process; co- } \\
\text { location of project staff } \\
\text { and/or designing 'arenas' } \\
\text { to encourage } \\
\text { communication among } \\
\text { project experts. }\end{array}$ & $\begin{array}{l}\text { Common identity, } \\
\text { unifying framework, } \\
\text { common deadline } \\
\text { pressure, shared } \\
\text { responsibilities; } \\
\text { establishing common } \\
\text { ground and a common } \\
\text { lexicon. }\end{array}$ & $\begin{array}{l}\text { Conflicts among } \\
\text { project staff; } \\
\text { disagreement } \\
\text { between disciplinary } \\
\text { experts; } \\
\text { incompatible } \\
\text { professional } \\
\text { requirements. }\end{array}$ \\
\hline \multicolumn{5}{|l|}{$\begin{array}{l}\text { 2. Interlanguage } \\
\text { dimension: elements of } \\
\text { interlanguage }\end{array}$} \\
\hline $\begin{array}{l}\text { a) Linguistic } \\
\text { representations }\end{array}$ & $\begin{array}{l}\text { Creation of } \\
\text { terminology, } \\
\text { metaphors, and } \\
\text { concepts that are } \\
\text { specific to the project } \\
\text { and that foster } \\
\text { coordination between } \\
\text { trained project experts } \\
\text { from diverse } \\
\text { disciplines. }\end{array}$ & $\begin{array}{l}\text { Role of figurative } \\
\text { language (metaphors and } \\
\text { analogies) in the } \\
\text { knowledge integration } \\
\text { process; foundational } \\
\text { role of a common } \\
\text { lexicon; creation of an } \\
\text { interlanguage that } \\
\text { transcends mere } \\
\text { translation and enables } \\
\text { coordination among } \\
\text { experts from various } \\
\text { disciplines. }\end{array}$ & $\begin{array}{l}\text { Developing a } \\
\text { pragmatic } \\
\text { interlanguage } \\
\text { that fosters } \\
\text { communication } \\
\text { among local } \\
\text { and specialized } \\
\text { languages. }\end{array}$ & $\begin{array}{l}\text { Difficulties } \\
\text { establishing a } \\
\text { common lexicon that } \\
\text { (i) makes sense to } \\
\text { everyone involved } \\
\text { and (ii) is } \\
\text { sufficiently } \\
\text { developed to reflect } \\
\text { the complexity of } \\
\text { both task and } \\
\text { technology. }\end{array}$ \\
\hline $\begin{array}{l}\text { b) Project } \\
\text { management } \\
\text { tools }\end{array}$ & $\begin{array}{l}\text { Use of project } \\
\text { management tools, } \\
\text { concepts, and methods } \\
\text { to integrate project } \\
\text { activities and } \\
\text { modules. }\end{array}$ & $\begin{array}{l}\text { The project management } \\
\text { toolbox as a mechanism } \\
\text { for improving project } \\
\text { coordination; specific } \\
\text { project management tools } \\
\text { (e.g., schedules, risk } \\
\text { registers) as 'boundary } \\
\text { objects'. }\end{array}$ & $\begin{array}{l}\text { Location of activities } \\
\text { in relation to each } \\
\text { other; understanding } \\
\text { project } \\
\text { interdependencies and } \\
\text { information needs } \\
\text { from downstream to } \\
\text { upstream activities } \\
\text { (and vice versa). }\end{array}$ & $\begin{array}{l}\text { Difficulties setting } \\
\text { up a logical } \\
\text { workflow that } \\
\text { matches the } \\
\text { knowledge } \\
\text { development process } \\
\text { before a common } \\
\text { understanding of } \\
\text { both product and } \\
\text { process has been } \\
\text { established. }\end{array}$ \\
\hline $\begin{array}{l}\text { c) Material } \\
\text { representations }\end{array}$ & $\begin{array}{l}\text { Production and use of } \\
\text { physical objects that } \\
\text { facilitate the sharing } \\
\text { and integration of } \\
\text { knowledge. }\end{array}$ & $\begin{array}{l}\text { Artefacts, such as } \\
\text { prototypes, simulation } \\
\text { tools, and drawings, as } \\
\text { boundary objects with the } \\
\text { capacity to foster the } \\
\text { translation and } \\
\text { transformation of } \\
\text { knowledge; artefacts as } \\
\text { key coordination } \\
\text { mechanisms. }\end{array}$ & $\begin{array}{l}\text { Improved } \\
\text { coordination; } \\
\text { improved } \\
\text { understanding of } \\
\text { project goals and final } \\
\text { outcomes. }\end{array}$ & $\begin{array}{l}\text { Difficulties } \\
\text { establishing physical } \\
\text { artefacts in projects } \\
\text { when actors are } \\
\text { uninformed about } \\
\text { their tasks and/or } \\
\text { when conditions } \\
\text { change frequently. }\end{array}$ \\
\hline
\end{tabular}


An important point is that the interlanguage must be defined inclusively and link several different elements, each of which has received much scholarly attention but has not been analyzed as a constituent of interlanguage creation. This point recalls the two main obstacles for theory development discussed earlier in the paper: first, research must address the role and significance of an interlanguage and, in so doing, must revise our understanding of 'common lexicon'. We deal with the second main obstacle by addressing the framework's dynamic aspect - that is, how the interlanguage is actually created. To ensure the completeness and analytical relevance of our framework, we focus on this topic in the next section.

\section{Toward a process model of interlanguage creation in LSIPs}

Research on project-based organizing has emphasized the need for inquiry into the evolutionary and "becoming" nature of projects, both in general and for innovative projects in particular (Lundin \& Söderholm, 1995; Engwall \& Westling, 2004; Hogdson \& Cicmil, 2006). This seems especially pertinent when dealing with LSIPs, since their process challenges are both inherent and substantial (Beck \& Plowman, 2014) and have significant implications for coordination (Tuertscher et al., 2014).

One can better understand the emergence of coordination in LSIPs through our analysis of Galison's work - in particular, the Rad Lab project - because it reveals the phases of developing interlanguage for an LSIP. Figure 5 displays the identified phases of interlanguage creation, commencing with the creation of the interactive zone to foster interlanguage creation and then continuing through three distinct phases in which our model's elements continually progress and interact. The final phase is institutionalization of the developed interlanguage, which includes investigating how it might benefit coordination in other contexts and projects. These five phases of the process model are detailed next. This model is described in a linear way to simplify the presentation, although individual phases may well involve their own iterations. 


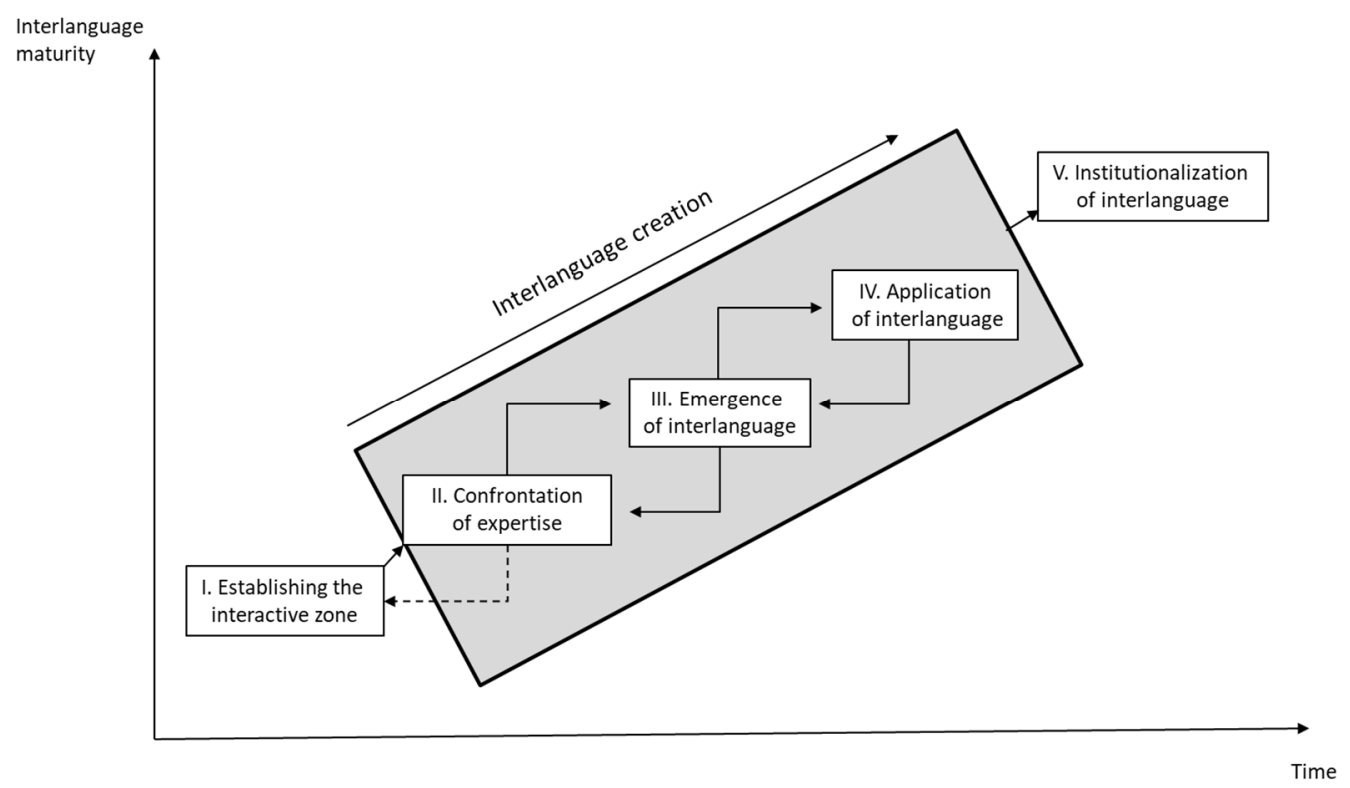

Phase I: Project creation. This phase involves setting up the project and creating the interactive zone. It includes establishing some kind of boundary around the people involved, stipulating a focus for conversations that will occur, and ensuring that project staff are aware of the individuals with whom they need to interact. Essential to this phase are various kinds of organizational delineations and co-location efforts: spatial, social, and mental. Also important are 'temporary decentralization' and autonomy, both of which promote interaction among participants (Bresnen et al., 2004). This phase corresponds to the initiation of the Rad Lab and highlights the organizational dimension as a critical prerequisite for interlanguage creation. Some components of an interlanguage may appear in this phase, albeit at an early stage of development; examples include PM tools to outline the technical challenge and identify interdependencies between the disciplinary areas involved. Also, material representations (including previous systems, products, etc.) may trigger communication and indicate the respects in which the new system or technologies should differ from the old.

Phase II: Expertise confrontation. Participant interaction during this phase typically includes disagreements among the experts involved, who have become more aware of the interactive zone's boundaries and other players. It is in this phase that the challenges of coordination identified by Carlile (2002; 2004), Kellogg et al. (2006), and Majchrzak et al. (2012) usually emerge. In many cases, the outcome is a collision of 
"thought worlds" (Dougherty, 1992), or "creative abrasion" (Leonard \& Swap, 1999) involving "contestation and justification" (Tuertscher et al., 2014). This scenario was encouraged by the Rad Lab's organization, which fostered direct interactions between scientists and engineers. Recall that Schwinger's first formulas resulted from such a clash of disciplines' paradigms. In this phase, individuals become increasingly aware of different viewpoints about the technological challenge and the project's key issues. Participants might have strongly differing opinions that create fundamental collaborative problems (Dougherty \& Dunne, 2011), which often involve both political and cognitive divides (Kaplan et al., 2017).

Phase III: Interlanguage emergence. In this phase, interactional expertise emerges, metaphors are presented to make conversations more meaningful, and new concepts are tried out through material representations; thus knowledge becomes “interlaced" (Tuertscher et al., 2014). Often the metaphors and concepts employed are taken from other fields - bridging the communities involved to shape a shared understanding and establish some mutual knowledge among groups of individual actors - and then redeveloped in interaction with others (Seidel \& O'Mahony, 2014). The equivalent circuits depicted in Figure 3 are typical of the coordination-enhancing interlanguage that can result. This phase sees the emergence of metaphors from different participating knowledge domains, as well as completely new concepts developed among the disciplines involved. However, the metaphors are still not sufficiently developed and integrated to form a coherent meaning.

Phase IV: Interlanguage application. This phase signals a more productive stage in which language barriers have been overcome and participants are focused on completing productive tasks and integrating knowledge across domain boundaries and areas of expertise. The interlanguage that developed in the Rad Lab served to facilitate coordination, between scientists and engineers, leading to the rapid design of several radically new devices and technologies. In this phase, the metaphors and artefacts suggested in the former phase are tested, revised, and tested again. They have matured and form a coherent meaning to the participants involved - integrating knowledge while still providing room for disciplinary distinctiveness. The interlanguage has also been integrated into multiple metaphors and concepts, not only in linguistic representations but also in material representations and PM tools. The coherence among these three elements 
is crucial to making the interlanguage fully operative and 'mature', which was also observed in the Rad Lab case. Interactions among the three elements establish that interlanguage is ingrained in the recombination and cogeneration of solutions (Majchrzak et al., 2012) and arises through the actual practice teaming (Edmondson, 2012).

Phase V: Interlanguage institutionalization. Sometimes the creole (or fragments of it) will be institutionalized and possibly re-used in other projects and other parts of the organizations involved in the project. Such exploitation of interlanguage could well constitute one of the most important outcomes of an innovative project in which the creole was originally developed. Thus, for example, the interlanguage created during the Radar Project was later institutionalized in textbooks: the figures analyzed by Galison (figure 3) were eventually published in Marcuvitz's Waveguide Handbooks - first printed in 1951 as volume 10 of the famous MIT Radiation Laboratory Series, which nurtured large parts of the nascent electronic industry after World War II. In this phase, a project's 'essential' outcome transcends the initial object of development to generate their spillover learning effects (Nonaka, 1994; Prencipe \& Tell, 2001). This phase also underscores the importance of the interplay among the three elements of interlanguage creation (linguistic representations, PM tools, and material representations) - as manifested by, for example, prototypes that demonstrate not only the interlanguage but also the process of its creation.

We synthetize our process model of interlanguage creation in Table 2, which shows how the coordination process may unfold in a rather idealistic sense yet similarly to what was observed in the Rad Lab case. With this synthesis we hope to strengthen our interlanguage theory of LSIPs by clarifying the links among their two key dimensions (organizing devices and interlanguage), the three elements of interlanguage (linguistic representations, PM tools, and material representations), and the five phases of our proposed model: project creation; expertise confrontation; and the emergence, application, and institutionalization of an interlanguage. We believe that this approach will make it easier for future research to test our theory. 
Table 2. Five Phases of Interlanguage Creation

\begin{tabular}{|c|c|c|c|c|}
\hline \multirow[b]{2}{*}{ Phase } & \multirow{2}{*}{$\begin{array}{c}\text { Organizational dimension: } \\
\text { Organizing devices }\end{array}$} & \multicolumn{3}{|c|}{ Interlanguage dimension } \\
\hline & & $\begin{array}{c}\text { Linguistic } \\
\text { representation }\end{array}$ & PM tools & $\begin{array}{c}\text { Material } \\
\text { representations }\end{array}$ \\
\hline $\begin{array}{l}\text { Phase I } \\
\text { Project creation }\end{array}$ & $\begin{array}{l}\text { Setting up of a formal project } \\
\text { organization. Establishing the } \\
\text { interactive zone to promote } \\
\text { interlanguage creation. Co- } \\
\text { location of key expertise to } \\
\text { ensure interaction and } \\
\text { intermingling of elements in } \\
\text { the process of interlanguage } \\
\text { creation. }\end{array}$ & $\begin{array}{l}\text { Overarching metaphors } \\
\text { rooted in disciplinary } \\
\text { contexts to drive the } \\
\text { collaborative process. }\end{array}$ & $\begin{array}{l}\text { Mission statement } \\
\text { clarifying overall } \\
\text { objective with the } \\
\text { venture. Tools intended } \\
\text { mainly for grasping } \\
\text { complexity and } \\
\text { uncertainty. }\end{array}$ & $\begin{array}{l}\text { Reference material } \\
\text { objects used for } \\
\text { stimulating the } \\
\text { creative process and } \\
\text { creating a project } \\
\text { vision. }\end{array}$ \\
\hline $\begin{array}{l}\text { Phase II } \\
\text { Expertise } \\
\text { confrontation }\end{array}$ & $\begin{array}{l}\text { Operational and brainstorming } \\
\text { meetings. Design sessions. } \\
\text { Ensuring workspaces for } \\
\text { furthering interaction to } \\
\text { promote interlanguage } \\
\text { creation. }\end{array}$ & $\begin{array}{l}\text { Tentative formulas; } \\
\text { provisional frameworks } \\
\text { rooted in disciplinary } \\
\text { contexts. }\end{array}$ & $\begin{array}{l}\text { Milestones to boost } \\
\text { collaboration. Overall } \\
\text { project plan established } \\
\text { to ensure temporal } \\
\text { synchronization of } \\
\text { knowledge integration } \\
\text { process. }\end{array}$ & $\begin{array}{l}\text { Design objects rooted } \\
\text { in disciplinary } \\
\text { contexts. Disciplinary } \\
\text { instrumentation. }\end{array}$ \\
\hline $\begin{array}{l}\text { Phase III } \\
\text { Interlanguage } \\
\text { emergence }\end{array}$ & $\begin{array}{l}\text { Emergence of an established } \\
\text { project and team spirit. } \\
\text { Members have developed the } \\
\text { work-related trust crucial for } \\
\text { effective collaboration among } \\
\text { disciplines and functions. }\end{array}$ & $\begin{array}{l}\text { New metaphors are } \\
\text { suggested, and new } \\
\text { formulas interlink several } \\
\text { disciplines. A creole } \\
\text { emerges within the team. }\end{array}$ & $\begin{array}{l}\text { Architectures and } \\
\text { system properties have } \\
\text { emerged that are central } \\
\text { to driving collaboration } \\
\text { in a novel way, } \\
\text { matching the technical } \\
\text { and scientific } \\
\text { achievements. }\end{array}$ & $\begin{array}{l}\text { Boundary objects have } \\
\text { been tried out. } \\
\text { Prototypes have been } \\
\text { developed and some } \\
\text { physical artefacts exist } \\
\text { that encourage } \\
\text { knowledge sharing } \\
\text { and idea exchange. }\end{array}$ \\
\hline $\begin{array}{l}\text { Phase IV } \\
\text { Interlanguage } \\
\text { application }\end{array}$ & $\begin{array}{l}\text { Project boundaries become } \\
\text { increasingly stabilized, roles } \\
\text { and responsibilities clarified, } \\
\text { interaction channels better } \\
\text { defined. }\end{array}$ & $\begin{array}{l}\text { Use of tentative } \\
\text { metaphors and formulas. } \\
\text { The interlanguage } \\
\text { becomes increasingly } \\
\text { sophisticated and widely } \\
\text { used. Interlanguage with } \\
\text { its key terms and } \\
\text { meanings becomes } \\
\text { integral to the project's } \\
\text { coordination activities. }\end{array}$ & $\begin{array}{l}\text { Central hypotheses and } \\
\text { propositions are tested } \\
\text { as integral parts of the } \\
\text { project. Goals are } \\
\text { revisited on a recurrent } \\
\text { basis. Interfaces are } \\
\text { redefined and planning } \\
\text { procedures clarified. }\end{array}$ & $\begin{array}{l}\text { Boundary objects have } \\
\text { advanced and are now } \\
\text { relatively stabilized. } \\
\text { Instruments have been } \\
\text { developed that allow } \\
\text { knowledge sharing } \\
\text { among various } \\
\text { disciplines. }\end{array}$ \\
\hline $\begin{array}{l}\text { Phase IV } \\
\text { Interlanguage } \\
\text { institutionalization }\end{array}$ & $\begin{array}{l}\text { Organizational solutions } \\
\text { transferred as part of the } \\
\text { institutionalization of an } \\
\text { interlanguage. }\end{array}$ & $\begin{array}{l}\text { Publication, as in } \\
\text { handbooks and } \\
\text { textbooks, of material } \\
\text { summarizing key parts of } \\
\text { the interlanguage. }\end{array}$ & $\begin{array}{l}\text { Project management } \\
\text { tools transferred as part } \\
\text { of new organizational } \\
\text { solutions to foster and } \\
\text { store the established } \\
\text { interlanguage. }\end{array}$ & $\begin{array}{l}\text { Design objects and } \\
\text { physical products exist } \\
\text { that store central } \\
\text { knowledge emerging } \\
\text { from the project. } \\
\text { These objects function } \\
\text { as material } \\
\text { representations that } \\
\text { are central to the } \\
\text { interlanguage. }\end{array}$ \\
\hline
\end{tabular}

\section{Discussion}

Our framework enriches the existing literature on coordination across knowledge boundaries during time-centric and goal-oriented innovation processes. Prior literature within this area demonstrates that addressing how coordination unfolds requires a multi- 
dimensional perspective. The research presented in this paper has emphasized the roles of the organization in project creation, of specific actors (e.g., gatekeepers, boundary spanners), and of students in "symbiont practices" with new instruments (Kaplan et al., 2017). The literature has also provided in-depth analysis of cross-boundary coordination processes (Carlile, 2002; Kellogg et al., 2006; Majchrzak et al., 2012; Tuertscher et al., 2014). While the significance of establishing a common lexicon is widely acknowledged, we identify gaps in the literature regarding the nature of such a lexicon and the process by which it emerges.

This paper makes four specific contributions. First and foremost, we point out that the challenge of coordination is not simply that of agreement on terms, as a 'common lexicon' is most often interpreted. A LSIP's very existence depends on its functioning as a trading zone that enables the creation of an interlanguage. The originality of Galison's approach lies in recognizing the need for such projects to create a new and "powerful, locally understood language" (1997, p. 833) with the capacity to facilitate coordination among the individuals and organizations involved. Galison emphasizes that this language amounts to much more than a 'translation' between disciplines or the agreement on a common lexicon. In fact, our second contribution is establishing that the content of this interlanguage was not part of the involved disciplines' prior practices. As discussed in our analysis of the Rad Lab project, this coordination challenge is acute in projects characterized by knowledge specialization because specialized knowledge is associated with idiosyncratic jargon and strong interdependencies - which create the need for an interlanguage to foster coordination among these specialists. This is where Julian Schwinger's formulas played a fundamental role. An interlanguage ideally maintains disciplinary expertise and language distinctiveness while allowing for the integration of diverse local languages to integrate highly differentiated knowledge bases.

Our third contribution consists of elaborating on Galison's argument that the definition of interlanguage be extended to include more than "just words" - components that are not captured by the 'common lexicon' notion. Thus, we identify three such components of an interlanguage intended to coordinate innovation: linguistic representations, project management tools, and material representations. These three elements have in common the effect of fostering coordination across knowledge interfaces in contexts characterized by high degrees of task uniqueness and 
interdisciplinarity. This extended definition improves the analysis of interlanguage by including not only linguistic representations but also boundary objects and management tools; the insights derived from these perspectives improve our understanding of how an interlanguage is created and hence of the coordination that emerges in these settings.

Fourth, our framework helps bridge the structural approach (as presented in Lawrence and Lorsch, 1967, and others in our literature review) and the processual approach (e.g. Allen, 1977; Carlile, 2002) to coordination. This framing creates a more current and nuanced understanding of the coordination problem in LSIPs. More specifically, we demonstrate that the structural features play a key role in the process of creating an interlanguage to foster coordination in LSIP. For instance, the decision to initiate the Rad Lab project, combined with its physical layout, established an interactive zone that laid the foundation for the temporary trading zone where a new interlanguage could be created (see also Galison, 1997, p. 831). This insight should lead researchers to study the dynamic interactions between structures and processes of coordination.

These four contributions lead us to emphasize both the processual nature of innovative projects and the ongoing creation of interlanguage as figuring prominently in any account of the fundamental problem of coordination. In so doing, we contribute to the literatures on innovative projects (Brady \& Davies, 2004; Lenfle, 2008; Obstfeld, 2012) and boundary-spanning mechanisms (Carlile, 2004; Kellogg et al., 2006; Majchrzak et al., 2012) by illustrating a prime reason for establishing these projects. Besides adding nuance to the discussion of language by comparing the breadth of an 'interlanguage' with that of a 'common lexicon', we foreground the need to view any interlanguage as a continuously evolving part of the project and as an integral feature of the coordination process. Although many scholars have remarked on the importance of establishing a language that allows for communication across disciplinary boundaries (Carlile, 2002; Majchrzak et al., 2012), few have taken an interest in the actual creation of such language. Hence, our paper offers a novel perspective to the problem of coordination in these extreme settings.

\section{Future research and implications}

Our findings and contributions point to several interesting questions for future research. First, a deeper study of the respective roles played by an interlanguage's different 
elements (linguistic representations, PM tools, and material representations) and their interaction is sorely needed. The importance of such roles is demonstrated powerfully by the role of Schwinger's formula in the Rad Lab case, and Galison's (1997) book also includes interesting cases of the influence of PM tools. However, the extant results remain quite dispersed. A fine-grained and integrated analysis of the emergence, role, and interaction of these elements is clearly merited. Such analysis would enrich the emerging literature that engages earlier work on cross-boundary coordination (Kellogg et al., 2006; Majchrzak et al., 2012; Nicoloni et al., 2012; Seidel \& O’Mahony, 2014).

A second avenue worth investigating is to study the interaction between the interactive zone and interlanguage creation. The Rad Lab case demonstrates the necessity of co-location and of having a common space for actors so that communication will be enhanced. These features likely reflect the task's highly innovative nature, which required the physical presence of all experts involved. Along similar lines, Kaplan et al. (2017) highlight the contribution of individuals" "symbiont practices" with instruments to spanning boundaries within novel interdisciplinary projects in 'academic contexts'. Whether such practices are viable also in LSIP projects remains to be studied. Here two questions arise. The first question (see Grabher \& Ibert, 2014) concerns the extent to which these qualities could be established also in dispersed projects and virtual communities. The second question concerns the variety of knowledge processes across boundaries in relation to particular physical layout. In that respect, studying how different physical layouts influence the creation of an interactive zone and how that in turn influences the process of interlanguage creation would be highly relevant (in other domains, see de Vaujany \& Vaast, 2014 on the interaction between organizational space and legitimacy). The last (and perhaps most obvious) avenue that we should point out is to test the applicability of our process model to other innovative settings - and also to less innovative settings. Recall that this model is an exploratory proposal based on a restricted set of cases. Further research is needed to define its boundary conditions and to refine both the content of the different phases and the connections among them.

Finally, we believe that this practice-oriented theory and conceptual framework have important methodological implications. This theory calls for a strong engagement in the actual work and practices of the actors involved in these projects (Blomquist et al., 2010; Majchrzak et al., 2012). Only by analyzing in real and dynamic contexts the micro- 
mechanisms of coordination will we be able to understand how LSIPs evolve and how coordination processes emerge in them and in other innovative projects. Indeed, our findings should encourage management scholars to embrace the possible advantages of engaging in interdisciplinary research to study the emergence of a new interlanguage. A compelling option is to collaborate with linguistics, as Galison did, and thereby strengthen the theoretical foundation of interlanguage and its emergence (for a recent example in the project management's field, see Neukirch-Musca et al., 2014). One can well imagine scholars themselves playing a key role in such processes and -taking part in the creation of a new interlanguage - so they can more fully understand the emergence of coordination in innovative settings.

\section{References}

Allen, T. J. (1977). Managing the Flow of Technology. Cambridge, MA: The MIT Press.

Ancori, B, Bureth, A. \& Cohendet, P. 2000. The Economics of Knowledge: The Debate about Codification and Tacit Knowledge. Industrial and Corporate Change 9(2): 255-287.

Beck, T. E. \& Plowman, D. A. (2014). Temporary, emergent interorganizational collaboration in unexpected circumstances: A study of the Columbia space shuttle response effort. International Journal of Project Management, 25, 4, 1234-1252.

Berggren, C., Bergek, A., Bengtsson, L., Hobday, M. \& Söderlund, J. (eds.) (2011). Knowledge Integration and Innovation. Critical Challenges Facing International Technology-Based Firms. Oxford: Oxford University Press.

Blomquist, T. Hällgren, M., Nilsson, A. \& Söderholm, A. (2010). Project-as-Practice: In Search of Project Management Research That Matters. Project Management Journal, 41(1), 516.

Brady, T. \& Davies, A. (2004). Building Project Capabilities: From Exploratory to Exploitative Learning. Organization Studies, 25(9), 1601-21.

Bresnen, M., Goussevskaia, A. \& Swan, J. (2004). Embedding New Management Knowledge in Project-Based Organizations. Organization Studies, 25(9), p. 1335-55.

Brown, L. 1999. A Radar History of Word War II. Bristol and Philadelphia: Institute of Physics Publishing.

Brusoni, S. (2005): The Limitations to Specialization: Problem Solving and Coordination in 'Modular Networks'. Organization Studies, 26(2), 1885-1907.

Brusoni, S., Prencipe, A. \& Pavitt, K. (2001). Knowledge Specialization, Organizational Coupling, and the Boundaries of the Firm: Why Do Firms Know More Than They Make? Administrative Science Quarterly, 46(4), 597-621.

Buderi, R. (1996). The Invention That Changed the World. How a Small Group of Radar Pioneers Won the Second World War and Launched a Technical Revolution. New York: Touchstone.

Callon, M. (1986). Some Elements of a Sociology of Translation: Domestication of the Scallops and the Fishermen of St Brieuc Bay, pp. J. Law (ed.), Power, Action and Belileve: A New sociology of knoweldge, London: Routledge.

Carlile, P. (2002). A Pragmatic View of Knowledge and Boundaries : Boundary Objects in New Product Development. Organization Science, 13(4), 442-55. 
Carlile, P. (2004). Transferring, Translating, and Transforming: An Integrative Framework for Managing Knowledge across Boundaries. Organization Science, 15(5), 555-68.

Cattani, G., Ferriani, S., Mariani, M. \& Mengoli, S. (2013). Tackling the "Galacticos" Effect: Team Familiarity and the Performance of Star-Studded Projects. Industrial and Corporate Change, 22(6), 1629-62.

Chang, A., Hatcher, C. \& Kim, J. (2013). Temporal Boundary Objects in Megaprojects: Mapping the System with the Integrated Master Schedule. International Journal of Project Management, 31, 323-32.

Clark, K. \& Fujimoto, T. (1991). Product Development Performance. Strategy, Organization and Management in the World Auto Industry. Boston, MA.: Harvard Business School Press.

Corley, E., Boardman, P. \& Bozeman, B. (2006): Design and the Management of Multiinstitutonal Research Collaborations: Theoretical Implications from Two case Studies. Research Policy. 35, 975-993.

Cusumano, M \& Nobeoka, K. (1998), Thinking Beyond Lean. New York: The Free Press..

Davies, A. (2017). A Very Short Introduction to Project Management, Oxford: Oxford University Press.

Davies, A. (2013). Innovation and Project Management, in M. Dodgson, D. Gann \& N. Phillips (eds.), The Oxford Handbook of Innovation Management (pp.625-647). Oxford: Oxford University Press.

Davies, A., Gann, D. \& Douglas, T. (2009). Innovation in Megaprojects: System Integration at London Heathrow Terminal T5. California Management Review, 51(2), 101-25.

de Vaujany F-X \& Vaast E. (2013). If These Walls Could Talk: The Mutual Construction of Organizational Space and Legitimacy. Organization Science, 25(3), 713-731.

Dougherty, D. (1992). Interpretive Barriers to Successful Product Innovation in Large Firms. Organization Science, 3(2), 179-202.

Dougherty, D. \& Dunne, D. (2011). Organizing Ecologies for Complex Innovation. Organization Science, 22(5), 1214-1233.

Edmondson, A. (2012). Teaming: How Organizations Learn, Innovate and Compete in the Knowledge Economy, New York: Jossey-Bass.

Edmondson, A. C. \& Reynolds, S. (2015). Building the Future: Big Teaming for Audacious Innovation. New York: Berrett Koehler Publishers.

Enberg, C., Lindkvist, L. \& Tell, F. (2006). Exploring the Dynamics of Knowledge Integration: Acting and Interacting in Project Teams. Management Learning, 6(1), 143-65.

Engwall, M. (2003). No Project Is an Island: Linking Projects to History and Context. Research Policy, 32(5), 789-808.

Engwall, M. (2012). PERT, Polaris and the Realities of Project Execution. International Journal of Managing Projects in Business, 5(4), 595-616.

Engwall, M \& Westling, G. (2004). Peripety in an R\&D Drama: Capturing a Turnaround in Project Dynamics. Organization Studies, 25(9), 1557-78.

Ewenstein, B. \& Whyte, J. (2009). Knowledge Practices in Design: The Role of Visual Representations as 'Epistemic Objects'. Organization Studies, 30(1), 7-30.

Floyd, S. (2009). 'Borrowing' Theory: What Does This Mean and When Does It Make Sense in Management Scholarship? Journal of Management Studies, 46(6), 1057-58.

Flyvbjerg, B. (2017). Introduction: The Iron Law of Megaproject Management, in B. Flyvbjerg (ed.), The Oxford Handbook of Megaproject Management. Oxford: Oxford University Press.

Galison, P. (1997). Image and Logic: A Material Culture of Microphysics. Chicago: Chicago University Press.

Galison, P. (2010). Trading with Enemy, in M. Gorman (ed.), Trading Zones and Interactional Expertise. Cambridge, (pp. 25-52), MA: The MIT Press.

Galison, P. \& Hevly, B. W. (1992). Big Science: The Growth of Large-Scale Research. Stanford: Stanford University Press. 
Geraldi, J. (2009). What Complexity Assessments Can Tell Us About Projects: Dialogue between Conception and Perception. Technology Analysis and Strategic Management 21(5): 665678, 21(5), 665-678.

Gorman, M. (2002). Levels of Expertise and Trading Zones. A Framework for Multidisciplinary Collaboration. Social Studies of Science, 32(5/6), 933-38.

Gorman, M., Groves, JF. \& Schrager, J. (2004). Societal Dimensions of Nanotechnology as a Trading Zone: Results from a Pilot Project in D. Baird, A. Nordmann \& J. Schummer, Discovering the Nanoscale, (pp. 63-73),Amsterdam: IOS Press.

Grabher, G. \& Ibert, O. (2014). Distance as Asset? Knowledge Collaboration in Hybrid Virtual Communities, Journal of Economic Geography, 14, 97-123.

Groves, L. (1962). Now It Can Be Told: The Story of the Manhattan Project, New York: Harper Row.

Gulati, R., Wholgezogen, F. \& Zhelyakov, P. (2012). The Two Facets of Collaboration: Cooperation and Coordination in Strategic Alliances. Academy of Management Annals, 6, 531-83.

Haerem, T., Pentland, B. \& Miller, K. (2015). Task Complexity: Extending a Core Concept. Academy of Management Review, 40(3), 446-460.

Henderson, K. (1999). On Line and on Paper: Visual Representations, Visual Culture, and Computer Graphics in Design Engineering. Cambridge: MIT Press.

Hodgson, D. \& Cicmil, S. (eds.) (2006). Making Projects Critical. New York: Palgrave.

Hoffmann, S., Pohl, C. \& Hering, J. (2017). Exploring Transciplinary Integration within a Large Research Program: Empirical Lessons from Four Thematic Synthesis Processes. Research Policy, 46(3): 678-692.

Hoopes, D., \& Postrel, S. (1999). Shared Knowledge, 'Glitches', and Product Development Performance. Strategic Management Journal, 20, 837-65.

Iansiti, M. \& Clark, K. (1994). Integration and Dynamic Capabilities: Evidence from Product Development in Automobiles and Mainframe Computers. Industrial and Corporate Change, 3(3), 507-605.

Ioro, J. \& Taylor, J. (2014). Boundary Object Efficacy: The Mediating Role of Boundary Objects on Task Conflict in Global Virtual Project Networks. International Journal of Project Management, 32, 7-17.

Johnson, S. (2002). The Secret of Apollo. Systems Management in American and European Space Programs. Baltimore: The John Hopkins University Press.

Jullien, B., Lung, Y. \& Midler, C. (2013). The Logan Epic. Paris: Dunod.

Kaplan, S., Milde, J. \& Schwartz-Cowan, R. (2017). Symbiont Practices in Boundary Spanning: Bridging the Cognitive and Political Divides in Interdisciplinary Research. Academy of Management Journal, 60(4), 1387-1414.

Kellogg, K., Orlikowski, W. \& Yates, J. (2006). Life in the Trading Zone: Structuring Coordination Accross Boundaries in Postbureaucratic Organizations. Organization Science, 17(1), 22-44.

Komendantova, N., Barras, L., Patt, A. \& Battaglini, A. (2012). Perceptions of Risks in Renewable Energy Projects: The Case of Concentrated Solar Power in North Africa. Energy Policy, 40, 103-109.

Lawrence, R. \& Lorsch, JW. (1967). Differentiation and Integration in Complex Organizations. Administrative Science Quarterly, 12(1), 1-47.

Lenfle, S. (2008). Exploration and Project Management. International Journal of Project Management, 26(5), 469-78.

Leonard, D. \& Swap, W. (1999). When Sparks Fly. Harnessing the Power of Group Creativity. Boston: Harvard Business School Press.

Ligthart, R, Oerlemans, L \& Noorderhaven, N. (2016). In the Shadows of Time: A Case Study of Flexibility Behaviors in an Interorganizational Project. Organization Studies 37(12): $1721-1743$. 
Lindkvist, L. (2005). Knowledge Communities and Knowledge Collectivities: A Typology of Knowledge Work in Groups. Journal of Management Studies, 42(6), 1189-210.

Lindkvist, L., Söderlund, J. \& Tell, F. (1998). Managing Product Development Projects: On the Significance of Fountains and Deadlines. Organization Studies, 19(6), 931-951.

Linehan, C. \& Kavanagh, D. (2006). From Project Ontologies to Communities of Virtue, in D. Hodgson and S. Cicmil, Making Projects Critical. (pp. 51-67), New York: Palgrave.

Majchrzak, A., More, P. \& Faraj, S. (2012). Transcending Knowledge Differences in CrossFunctional Teams. Organization Science, 23(4), 951-70.

Manning, S. (2017). The rise of project network organizations: Building core teams and flexible partner pools for interorganizational projects. Research Policy, 46, 1399-1415.

Manning, S. \& Sydow, J. (2011). Projects, Paths, and Practices: Sustaining and Leveraging Project-Based Relationships. Industrial and Corporate Change, 20(5), 1369-402.

Markóczy, L. \& Deeds, D. (2009). Theory Building at the Intersection: Recipe for Impact or Road to Nowhere? Journal of Management Studies, 46(6), 1076-90.

Midler, C. (1996). L'auto Qui N'existait Pas. Paris, France: Dunod.

Midler, C. (2013). Implementing a Low-End Disruption Strategy through Multiproject Lineage Management: The Logan Case. Project Management Journal, 44(5), 24-35.

Morris, P. (2013). Reconstructing Project Management. Oxford: Wiley-Blackwell.

Morris, P., Pinto, J. \& Söderlund, J. (eds.) (2011). The Oxford Handbook of Project Management. Oxford: Oxford University Press.

Morris, P. (2015). IRNOP Keynote Plenary Session on Projects and Climate Change. IRNOP Conference, University College London.

Moss-Kanter, R. (1990). When Giants Learn to Dance. New-York: The Free Press.

Nicolini, D., Mengis, J. \& Swan, J. (2012). Understanding the Role of Objects in CrossDisciplinary Collaboration. Organization Science, 23(3), 612-19.

Neukirch Musca, G., Mellet, C., Simoni, G., Sitri, F., \& deVogüe, S. 2014. “Drop your boat!": The discursive co-construction of project renewal. The case of the Darwin mountaineering expedition in Patagonia. International Journal of Project Management, 32(7): pp.1157-1169.

Nonaka, I. (1994). A Dynamic Theory of Organizational Knowledge Creation. Organization Science, 5(1), 14-37.

Nonaka, I. \& Takeuchi, H. (1995). The Knowledge-Creating Company. Oxfrod: Oxford University Press.

Obstfeld, D. (2012). Creative Projects: A Less Routine Approach toward Getting New Things Done. Organization Science, 23(6), 1571-92.

Okhuysen, G. \& Bechky, B. (2009). Coordination in Organizations: An Integrative Perspective. Academy of Management Annals, 3(1), 463-502.

Pettigrew, A., Whittington, R., Melin, L., Sanchez-Runde, C. \& Mumagami, T. (Eds.), (2003). Innovative Forms of Organizing, London: Sage.

Prencipe, A. \& F. Tell (2001): Inter-project Learning: Processes and Outcomes of Knowledge Codification in Project-based Firms. Research Policy, 30(9), 1373-1394.

Sapolsky, H. (1972). The Polaris System Development. Cambridge, MA: Harvard University Press.

Sapsed, J. \& Salter, A.(2004). Postcards from the Edge: Local Communities, Global Programs and Boundary Objects. Organzation Studies, 25(9), 1515-34.

Scott, R., Levitt, R. E. \& Orr, R. J. (eds) (2011). Global Projects: Institutional and Political Challenges, Cambridge: Cambridge University Press.

Scranton, P. (2014): Projects as a Focus for Historical Analysis: Surveying the Landscape, History and Technology, 30(4), 354-373.

Seidel, V. \& O'Mahony, S. (2014). Managing the Repertoire: Stories, Metaphors, Prototypes, and Concept Coherence in Product Innovation. Organization Science, 25(3), 691-712.

Sole, D. \& Edmondson, A. (2002). Situated Knowledge and Learning in Dispersed Teams. British Journal of Management, 13(2), 17-34. 
Spinardi, G. (1994). From Polaris to Trident: The Development of Us Fleet Ballistic Missile Technology. Cambridge: Cambridge University Press.

Star, SL. \& Griesemer, R. (1989). Institutional Ecology, 'Translations' and Boundary Objects: Amateurs and Professionals in Berkeley's Museum of Vertebrate Zoology, 1907-39. Social Studies of Science, 19(3), 387-420.

Sydow, J., Lindkvist, L. \& DeFillippi, R. (2004). Project-Based Organizations, Embeddedness and Repositories of Knowledege: Editorial. Organization Studies, 25(9), 1475-89.

Tell, F. (2011). Knowledge Integration and Innovation: A Survey of the Field, in C. Berggren, A. Bergek, L. Bengtsson, M. Hobday \& J. Söderlund, Knowledge Integration and Innovation. Critical Challenges Facing International Technology-Based Firms. Oxford: Oxford University Press, 20-58.

Tell, F., Berggren, C., Brusoni, S. \& Van de Ven, A. (eds.), (2016) Managing Knowledge Integration across Boundaries Oxford: Oxford University Press.

Tsoukas, H. (2009). A Dialogical Approach to the Creation of New Knowledge in Organizations. Organization Science. 20(6), 941-957.

Tuertscher, P; R Garud \& A Kumaraswamy. (2014). Justification and Interlaced Knowledge at Atlas - CERN. Organization Science, 25(6), 1579-1608.

Tukiainen, S. \& Granqvist, N. (2016). Temporary Organizing and Institutional Change. Organization Studies 37(12): 1819-1840.

Tushman, M. \& P. Anderson. 1986. Technological Discontinuities and Organizational Environments. Administrative Science Quarterly, 31(3), 439-65.

Valentine, M.A. \& Edmonson, A. (2015). Team Scaffolds: How Mesolevel Structures Enable Role-Based Coordination in Temporary Groups. Organization Science, 25(2), 405-22.

Van de Ven, A. (1986). Central Problems in the Management of Innovation. Management Science, 32(5), 590-607.

Vaughan, D. (1999). The Role of the Organization in the Production of Techno-Scientific Knowledge. Social Studies of Science, 29(6), 913-943.

von Hippel, E. (1990). Task Partitioning: An Innovation Process Variable. Research Policy, 19, 407-418.

Weick, K. (1979). The Social Psychology of Organizing. Reading, MA: Addison-Wesley.

Whitley, R. (2006). Project-based Firms: New Organizational Form or Variatinos on a Theme. Industrial and Corporate Change. 15(1), 77-99.

Yakhlef, A. (2010). The Three Facets of Knowledge. A Critique of Practice-based Learning Theory. Research Policy, 39(1), 39-46.

Yakura, E.K. (2002). Charting Time: Timelines as Temporal Boundary Objects. Academy of Management Journal, 45(5), 956-70. 